\title{
Organizational Factors and Safety: the Mediation Effects of Organizational Processes
}

\author{
SHI Wei \\ Institute of Psychology, Chinese Academy of Sciences \\ Graduate University of Chinese Academy of Sciences \\ Beijing, P.R.China
}

\begin{abstract}
The research of safety related organizational factors is hampered for two reasons: 1 , accident retrospect analysis is always single-direction, it is hard to make conclusion what is the effect of some organizational factors even some accident analysis find they are safety related. 2 , latent failure, as a core concept in the field of organizational safety, still has not been studied at the level of detailed description. In this study, we use organizational process analysis to show the relationship between organizational factors and safety. Results from 391 employees' questionnaire investigation show that organization processes are the mediate between the organizational factors and safety. Latent failure, which comes from some negative characteristics of organizational factors, could be represented by the negative condition of organizational processes.
\end{abstract}

Keywords-organizational factors, safety, processes

\section{INTRODUCTION}

Organizational factors have been paid much attention on the research of organizational accidents since 1990s[1]. Many researchers found that besides human factors, some organizational factors contribute much to the real happen of accidents $[1,2]$. The concept of organizational errors has been cited to show the relationship between accidents and organizational factors [3].

Based on the accident analysis, many organizational factors have been cited that have close relationship with accidents [16]: Such as centralization of authority, weak organizational culture, lack of top-level safety commitment, etc. More and more researchers and company managers began to pay much attention on theses organizational factors and wish to improve the safety of the organizations. But nearly all theses studies are single-direction. That means through the accidents analysis, these organizational factors have been found have close relationship with the accidents, but we still know little about the effect of these organizational factors before the real accidents happen [7]. For example, many accident analysis reports cited that organizational structure is one key reason for the accident, but there is no detailed introduction on how organizational structure affect the organization before the real accident happen, there is either no detailed introduction on what the organization will be if the organizational structure is not as suitable as is should be.

Some concepts such as "incubation period" [8] or "latent failure" [3] were used to show the effect of some organizational factors before the real happen of accidents. It seems that it is

\author{
WANG Erping \\ Center for Social \& Economic Behavior \\ Institute of Psychology, Chinese Academy of Sciences \\ Beiijng, P.R.China
}

the way to know further about the relationship between organizational factors and accidents. But still by now, there is no detailed description of what is latent failure [9]. Based on the IPO model of organization. If we view the accidents are the outcome condition of the organization, organizational factors are the input, latent failure must be in the period of organizational process. Thus, organizational process analysis should be the bridge between the organizational factors and accidents.

For the complexity of organization, there is no fixed definition of organizational process [10]. Though different researchers have different opinions on what is organizational process, information communication process and power process is always the kernel of the organizational processes [11]. In their theories, information process is about how information is transported in the organization. Power process refers to the relationship of different levels in the organization. In this study, we will induct the information communication process and power process as the bridge to explore the relationship between organizational factors and organizational safety.

Thus, we posit that:

Hypothesis 1: Organizational factors are positively related to safety.

Hypothesis 2: Organizational factors are positively related to organizational processes.

Hypothesis 3: Organizational processes mediate the relationship between organizational factors and safety.

\section{METHOD}

\section{Samples}

Three hundreds and ninety one employees from 32 companies and hospitals were invited to participate in this study. Though the original aim is to analyses the data at both individual and organizational levels, the data at the organizational level is limited to be used at this time. So we have to give the analysis at individual level in this research period.

\section{Measures}

Each participant is asked to assess the characteristics of their organizations on a 5-scale questionnaire. Response 
choices range from 1 (strongly disagree) to 5 (strongly agree). The questionnaire is divided into three parts. The first part is organizational factors. Based on the organizational factor structure of Veen and Daft [12,13], we select four organizational factors that are always been cited in the accident analysis reports: organizational aim (5 items, $\alpha=.77$ ), technology(10 items, $\alpha=.85$ ), organizational structure( 8 items, $\alpha=.78)$ and organizational culture ( 6 items, $\alpha=.80$ ). All the items of this part are selected from Michigan organizational Assessment Questionnaire [14], Organization Assessment Survey [15] and National Organization Survey [16]. The second part of the questionnaire is organizational process that includes information communication process (12 items, $\alpha=.87$ ) and power process $(6$ items, $\alpha=.75)$. The items are from a pilot study in which group interview were used to describe the characteristics of organizational processes. The third part is about organizational safety ( 3 items, $\alpha=.88$ ).

\section{Analysis}

Structural equation modeling. Maximum likelihood structural equation modeling (SEM) was used to test our hypothesis.

\section{RESULTS}

\section{Scale Validation}

Table 1 displays descriptive statistics and correlations among all research variables at the individual level, providing preliminary evidence for the discriminative validity of the research constructs.

TABLE I. MEANS, SDS AND CORRELATION COEFFICIENTS OF ALL VARIABLES

\begin{tabular}{|l|l|c|c|c|c|c|c|c|}
\hline \multirow{2}{*}{\multicolumn{1}{|c|}{ Variables }} & \multicolumn{7}{|c|}{ Correlations } \\
\cline { 2 - 9 } & Mean & $\boldsymbol{S D}$ & $\mathbf{1}$ & $\mathbf{2}$ & $\mathbf{3}$ & $\mathbf{4}$ & $\mathbf{5}$ & $\mathbf{6}$ \\
\hline $\begin{array}{l}\text { 1.Organizational } \\
\text { Aim }\end{array}$ & 3.95 & .75 & & & & & & \\
\hline $\begin{array}{l}\text { 2.Organizational } \\
\text { Technology }\end{array}$ & 3.61 & .76 & .56 & & & & & \\
\hline $\begin{array}{l}\text { 3.Organizational } \\
\text { Structure }\end{array}$ & 3.56 & .82 & .57 & .64 & & & & \\
\hline $\begin{array}{l}\text { 4.Organizational } \\
\text { Culture }\end{array}$ & 3.96 & .78 & .59 & .63 & .72 & & & \\
\hline $\begin{array}{l}\text { 5.Information } \\
\text { Process }\end{array}$ & 3.65 & .74 & .53 & .58 & .75 & .76 & & \\
\hline 6.Power Process & 3.64 & .75 & .45 & .47 & .63 & .67 & .70 & \\
\hline 7.Safety & 4.15 & .76 & .52 & .53 & .59 & .63 & .60 & .59 \\
\hline
\end{tabular}

\section{Hypothesis Testing}

According to table 1, organizational aim, technology, organizational structure and culture are all significantly related to safety, information process and power process. $\mathrm{H} 1$ and $\mathrm{H} 2$ were supported. Then we explored the mediating role of organizational processes by SEM. Prior to this analysis, the overall factor structure of all research variables was examined at the individual level, which provided an adequate fit to the data $(\mathrm{N}=391), \chi 2 / \mathrm{df}=1.61(\mathrm{p}<.05) ; \mathrm{CFI}=.99 ; \mathrm{TLI}=.98 ; \mathrm{IFI}=$ .99 ; RMSEA $=.025$. These results verify the posited relationships among indicators and constructs, confirming the convergent validity and discriminant validity of the constructs.

According to $\mathrm{H} 3$, organizational processes will mediate the effects of the four organizational factors on organizational safety. Figure 1shows that power process is positively correlated with safety $(\gamma=.14, \mathrm{p}<.01)$ and organizational structure $(\gamma=.12, \mathrm{p}<.01)$ and organizational culture $(\gamma=.27$, $\mathrm{p}<.001)$ both are significantly correlated with power process. These results indicate that power process mediates the organizational structure and culture on organizational safety. Furthermore, the path from information process to power process was proved to be significant $(\gamma=.43, \mathrm{p}<.001)$. So, information process also mediates the organizational structure $(\gamma=.42, \quad \mathrm{p}<.001)$ and culture $(\gamma=.46, \quad \mathrm{p}<.001)$ on organizational safety. Moreover, organizational technology has a direct positive effect on organizational safety $(\gamma=.42$, $\mathrm{p}<.001)$ and organizational aim has an insignificant effect on organizational safety. Thus, $\mathrm{H} 3$ was partly supported.

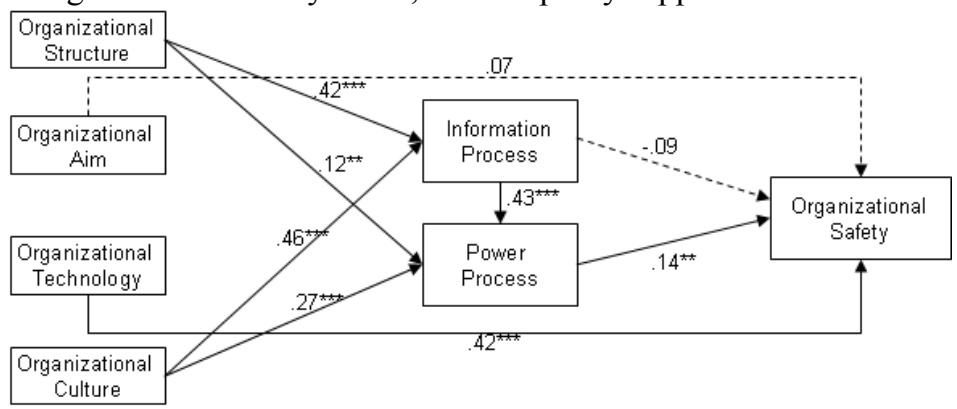

Figure 1. Estimated coefficients for the relationships among organizational factors, safety, and organizational processes. Standardized structural coefficients are reported. Model fit indexes: $\chi^{2}=1.31(\mathrm{p}=.22)$; comparative fit index $=.99$; Tucker-Lewis index $=.96$; incremental fit index $=.99$; root mean square error of approximation $=.059 .{ }^{* *} \mathrm{p}<.01,{ }^{* * *} \mathrm{p}<.001$

\section{DISCUSSION}

The study confirms that through the perception and evaluation of company employees, organizational factors do have close relation to organization safety. Except organizational aim, the other three organizational factors were proved have significant effect on organizational safety. To improve organization safety, we need pay much attention on these organizational factors such as technology, organizational structure and organizational culture.

It is a common sense that organizational technology has direct effect to organizational safety. With the technology improvement, accidents' number is decreased. But, we can find in the model that power process also significantly contributes to safety. I our study, power process include both the top to bottom command chain and bottom to top suggestion pathway. An organization will be unsafe if the power process is not fluent.

Organizational processes are the bridge between organizational factors and safety. In the study, organizational 
structure and culture affect the safety through the mediate effect of information communication process and power process. Besides the retrospect study of the accident analysis, these results give us another direction to view the relationship of organizational factors and organizational safety. For example, many accident analysis reports refer to that weak organizational culture could be a problem to safety. But it is hard to know how weak culture affects safety. In our model, we can find that organizational culture may affect safety through two paths: organizational culture affects power process, power process affects safety; organizational culture affects information process, then affects safety through power process.

It seems a reasonable way that using process analysis to represent latent failure. Some negative characteristics of organizational factor may not lead to the real happen of accident, but these factors may lead to the negative condition of the organizational process. In our study, centralization organizational structure obviously affects the accuracy of organizational information process. Production oriented organizational culture obviously affects the abundance of organizational information process. Thus, the inaccurate information process is the latent failure leaded by centralization organizational structure and inadequate information process is also the latent failure leaded by production oriented organizational culture.

\section{Practical Implications}

The findings have at least two important implications for management practices. Firstly, it is suggested that organizational process analysis is a important way to evaluate the organizational safety. If the information communication and power process are not fluent in an organization, we need to be more careful for the accident. The second implication is that when we appraise the safety of an organization, we should combine the information of organizational factors and organizational processes. Information of organizational factor will be more helpful if we know its effects on organizational processes.

\section{Future research}

In general, the study is just a valuable trial. Future research should try to establish the relationship of these constructs at organizational level. So, we need to collect more data from different organizations. Then, we may get the conclusion at the organizational level. Cause there is not an integrated description system on organizational processes, another future research is to extend the description system on organizational processes. We could know further about the organizational latent failure if we have more abundant description of organizational processes. We do believe that further study on this way will bring us a more clear comprehension on the relationship of organizational factors, organizational processes and safety.

\section{REFERENCES}

[1] Grabowski M, Roberts K H. Human and Organizational Error in Large Scale Systems. IEEE Transactions on Systems, Man and Cybernetics Part A: Systems and Humans, 1996, 26(1): 2 16

[2] Helmreich R. L., HG Schaefer. Team performance in the operating room. Human Error in Medicine, 1994 - Erlbaum

[3] Reason J. Human Error: A Systems Approach to Organizational Error. Ergonomics, 1995, 38(8): 1708 1721

[4] Rasmussen J, Nixon P. Human Error and the Problem of Causality in Analysis of Accidents. Philosophical Transactions of the Royal Society of London. Series B, Biological Sciences, 1990, 327(12): 449-462

[5] Perrow C. A Personal Note on Normal Accidents. Organization \& Environment, 2004, 17(1): 9-14

[6] Roberts K H. Organizational Errors: Catastrophic. International Encyclopedia of the Social and Behavioral Sciences, Vol. 16, Elsevier, 2001

[7] Hoff T, Jameson L, Hannan E. A Review of the Literature Examining Linkages between Organizational Factors, Medical Errors, and Patient Safety. Medical Care Research and Review, 2004, 61(1): 3 37

[8] Turner B A. Causes of Disaster: Sloppy Management. British Journal of Management, 1994, 5(3): 215 219

[9] Ramanujam R, Goodman P S. Latent Errors and Adverse Organizational Consequences: a Conceptualization. Journal of Organizational Behavior, 2003, 24(7): 815 836

[10] Garvin, D. The Process of Organization and Management. Sloan Management Review, 1998, Vol. 39(4), 33-50

[11] Raghu T S, Jayaraman B, Rao H R. Toward an Integration of Agent- and Activity-Centric Approaches in Organizational Process Modeling: Incorporating Incentive Mechanisms. Information Systems Research, 2004, 15(4): 316 335

[12] [12] Veen, P., Characteristics of Organizations, in Handbook of Work and Organizational Psychology, Edited by D. Drenth, H. Thierry, P. J. Willems and C. J. de Wolff, 1984, John Wiley \& Sons, Ltd

[13] Daft, R L. Organization theory and design. (6th Ed.).Cincinnati, Ohio: South Western College Publishing, 1998

[14] Cammann, C., Fichman, M., Jenkins, G.D., Klesh, J.R. (1983), "The Michigan organizational assessment questionnaire: assessing the attitudes and perceptions of organizational members", In Seashore, S.E., Lawler, E.E

[15] Kalleberg AL, Knoke D, et al. Organizations in America: Analyzing Their Structures and Human Resource Practice. Sage, 1996

[16] Muldrow TW, Buckley T, Schay BW, Creating high performance organizations in the public sector, Human Resources Management, 2002, 41(3): 341-354 